\title{
Effect of the Tower Type on the Gas Sweetening Process
}

\author{
Abdolkarim Sharifi and Elham Omidbakhsh Amiri* \\ Department of Chemical Engineering, University of Mazandaran, Babolsar - Iran \\ e-mail: e.omidbakhsh@umz.ac.ir \\ * Corresponding author
}

\begin{abstract}
The removal of acid gases, $\mathrm{CO}_{2}$ and $\mathrm{H}_{2} \mathrm{~S}$ from natural gas streams is essential for environmental and health reasons. In this work, the simulated gas sweetening unit with MethylDiEthanolAmine (MDEA) solvent was studied to improve quality. Firstly, the effect of trays types and then, the effect of various packing and the effect of the packing size were considered on the flow rate of $\mathrm{CO}_{2}$ and $\mathrm{H}_{2} \mathrm{~S}$ in the main streams. Results show that with considering the different trays types in the regenerator tower, the flow rate of $\mathrm{CO}_{2}$ in the sweet gas stream with bubble cap tray is lower than other trays types. Also, with considering the different trays types in the absorber tower, the flow rate of $\mathrm{CO}_{2}$ in the sweet gas stream with bubble cap tray is lower than other trays types in the absorber tower. In considering with different types of packing, results show that the flow rate of $\mathrm{CO}_{2}$ with ballast ring packing and the flow rate of $\mathrm{H}_{2} \mathrm{~S}$ with Raschig ring packing are lower than other types of packing. However, in some types such as cascade miniring, Intalox Saddles and pall ring, there is no difference for the flow rate of $\mathrm{CO}_{2}$ or $\mathrm{H}_{2} \mathrm{~S}$. In all cases, with increasing the size of the packing, the flow rate of $\mathrm{CO}_{2}$ and $\mathrm{H}_{2} \mathrm{~S}$ in the sweet gas stream increases, however, this increasing in the metal packing is very small.
\end{abstract}

\section{INTRODUCTION}

The growing needs of the natural gas in many of the industry lead to improving the existing processes for welfare of the people, energy and pollution control. One of the problems in the natural gas processing is the presence of acid gases such as $\mathrm{CO}_{2}$ and $\mathrm{H}_{2} \mathrm{~S}$. According to the contracts, specified $\mathrm{H}_{2} \mathrm{~S}$ and $\mathrm{CO}_{2}$ content in the natural gas stream would be about $4 \mathrm{ppm}$ and 2\%, respectively (Stewart and Arnold, 2011). The presence of these gases in the pipeline can cause technical problems (i.e. corrosion), so, before transferring of the natural gas through pipelines, these acid gases must be removed.

Many processes have been developed for the removal of $\mathrm{CO}_{2}$ and $\mathrm{H}_{2} \mathrm{~S}$ from the natural gas in various operating conditions and various $\mathrm{CO}_{2}$ and $\mathrm{H}_{2} \mathrm{~S}$ concentrations in the sour gas (Kohl and Nielsen, 1997; Processors, 2004; Rufford et al., 2012; Abdulrahman and Sebastine, 2013; Muhammad and GadelHak, 2014; Tavan and Tavan,
2014). One of these processes is the gas purification process by amine. The amines are the most generally accepted of the many available solvents for removal acid gas from the natural gas streams. First use of the amines for sweetening of the natural gas was referred to Bottoms who was given a patent in 1930. The amines to be used in the natural gas sweetening include MEA (MonoEthanolAmine), DiEthanolAmine (DEA), Tri-EthanolAmine (TEA), DiGlycolAmine (DGA), Methyl-DiEthanolAmine (MDEA) (Maddox, 1982).

MDEA is rapidly increasing in importance as a solvent for the removal of high concentrations of acid gas, particularly $\mathrm{CO}_{2}$, because of its low energy requirements in regenerator specially, high capacity, excellent stability, and other favorable attributes. On the other hand, capability of MDEA for selective reaction with $\mathrm{H}_{2} \mathrm{~S}$ in the presence of $\mathrm{CO}_{2}$ is important. Actually, when $\mathrm{CO}_{2}$ amount to $\mathrm{H}_{2} \mathrm{~S}$ amount be high, MDEA is used in this process (Maddox, 1982; Borhani et al., 2016). 
The gas sweetening processes by amine were developed to meet this need for a high pressure, high volume $\mathrm{H}_{2} \mathrm{~S}$ removal process. There are many cases that need to be considered to select a process for gas sweetening. These include:

- the different impurities to be removed from the natural gas stream;

- the concentration level of these impurities and the desired degree of separation would be achieved;

- the needed volume of the natural gas and the operation conditions of gas are set;

- the feasibility of sulfur recovery to be considered;

- relative economics of the suitable processes to be considered.

The level of acid gas concentration in the sour gas is an important issue for selecting the proper amine solvent and on the other influence on human health. Table 1 shows the allowable of $\mathrm{H}_{2} \mathrm{~S}$ concentrations for human contact time (Maddox, 1982).

Abdulrahman and Sebastine (2013) studied the effect of amine solvents types on the percent of $\mathrm{CO}_{2}$ and $\mathrm{H}_{2} \mathrm{~S}$ in the sweet gas stream. In their simulation, the optimization of process studied by using several amine types and blends of them, for example, MEA and MDEA. Also, they examined some of the critical factors for amine solvent types, such as solvent circulation rate and solvent concentration. They found that the use of (DEA $35 \% \mathrm{w} / \mathrm{w}$ ) is mostly recommended. Abu-Zahra et al. $(2007 \mathrm{a}, \mathrm{b})$ studied a parametric study of the technical and economic performance based on MEA. They found that with increasing the MEA concentration in the absorption solution, energy savings can be achieved. Higher efficiency of the regeneration can be seen by increasing the pressure. The costs of $\mathrm{CO}_{2}$ avoided and cost of electricity were found to show a shallow minimum for specification lean solvent loading. The highest concentration of MEA, if allowable from the corrosion point of view, can decrease the costs. Cho et al. (2015) studied amine-based acid gas sweetening with an emphasis on energy minimization. For the implementation of design and optimization of process, the process simulator Aspen HYSYS was linked to a stochastic optimization algorithm within MATLAB. With this configuration and operating conditions, the reboiler duty was significantly reduced and the overall utility costs are decreased.

Muhammad and GadelHak (2014) extracted the numerical output of the simulation by experimental design models for laboratory setups. The key variable and the total cost are related to the percent of $\mathrm{CO}_{2}$ and $\mathrm{H}_{2} \mathrm{~S}$ in the feed flow rate. Accordingly, the obtained relation is checked against different operating conditions to use for ensure the validity of the results. Tavan and Tavan (2014) noted that the absorption of $\mathrm{CO}_{2}$ into DEA is one of the most promising technologies for $\mathrm{CO}_{2}$ capturing due to its cost effectiveness, and capability of handling large amounts of acid gases. Azeotropic separation of ethane and $\mathrm{CO}_{2}$ with DEA was studied. In addition to, the effects of several variables were investigated.

In this work, the simulated gas sweetening unit with MDEA solvent was studied to improve quality and increase efficiency. In this unit, there are two towers, absorber and regenerator tower. Firstly, the two towers were studied as tray tower and investigated the effect of trays types such as valve, bubble cap and sieve tray on the flow rate of $\mathrm{CO}_{2}$ and $\mathrm{H}_{2} \mathrm{~S}$ in the main streams. Then, the regenerator tower was considered as a tower with bubble cap trays and the absorber tower was considered as a packed column and the effect of various packing, such as ballast ring, cascade mini ring, Intalox Saddles, pall rings, and Raschig rings and the effect of the packing size were considered on the flow rate of $\mathrm{CO}_{2}$ and $\mathrm{H}_{2} \mathrm{~S}$ in the main streams.

\section{DESCRIPTION OF THE PROCESS}

The general process for gas sweetening plant with amine is shown in Figure 1. The sour gas always enters the plant through a scrubber to remove any free liquids and entrained solid. The sour gas, then, enters the bottom of the absorber tower and flows upward through the tower in intimate counter current contact with the MDEA amine solution and then washed with water. Sweet gas cool after exiting the top of absorption tower, and then into the sweet gas dehydration to final use.

Amine absorbed acid gases with moving downwards and then rich amine (the amine solution with acid gases) leaves the bottom of the absorber tower. After this, rich amine enters to flash drum in order to separation gases and then temperature rises through the heat exchanger. Rich amine sends to the upper part of regeneration tower and flows through the lower section of the tower and heats with reboiler hot stream and acid gases are released that these gases are with amine steam. The gas passes into the condenser to become liquid amine and returns to the tower and finally acid gas comes out through the top of the flash drum. Recovered amine solution comes out from the bottom of the regenerator tower and then, cools with the passage of the heat exchanger and sent to a storage tank. Then, it mixes with the new amine and in the end, sent to the absorption tower.

\section{SIMULATION OF GAS SWEETENING PLANT}

The temperature, pressure and total flow rate of feed of the unit (sour gas) is $52{ }^{\circ} \mathrm{C}$ and 53.01 barg and $7154.8 \mathrm{kmol} / \mathrm{h}$, respectively. The composition of feed, based on mole fraction, is given in Table 2. Also, physical properties for the MDEA solvent are shown in Table 3 (Maddox, 1982). 
TABLE 1

$\mathrm{H}_{2} \mathrm{~S}$ concentration for human contact time (Maddox, 1982).

\begin{tabular}{c|c}
\hline Period of exposure & Parts of $\mathrm{H}_{2} \mathrm{~S}$ per million parts of air (ppm) \\
\hline Maximum allowable concentration for prolonged exposure & 10 \\
\hline Slight symptoms after exposure of several hours & $70-150$ \\
\hline $\begin{array}{c}\text { Maximum concentration that can be inhaled for } 1 \mathrm{~h} \text { without serious } \\
\text { consequences }\end{array}$ & $170-300$ \\
\hline Dangerous after exposure of 30 min to one hour & $400-500$ \\
\hline Fatal in exposure of 30 min or less & $600-800$ \\
\hline
\end{tabular}

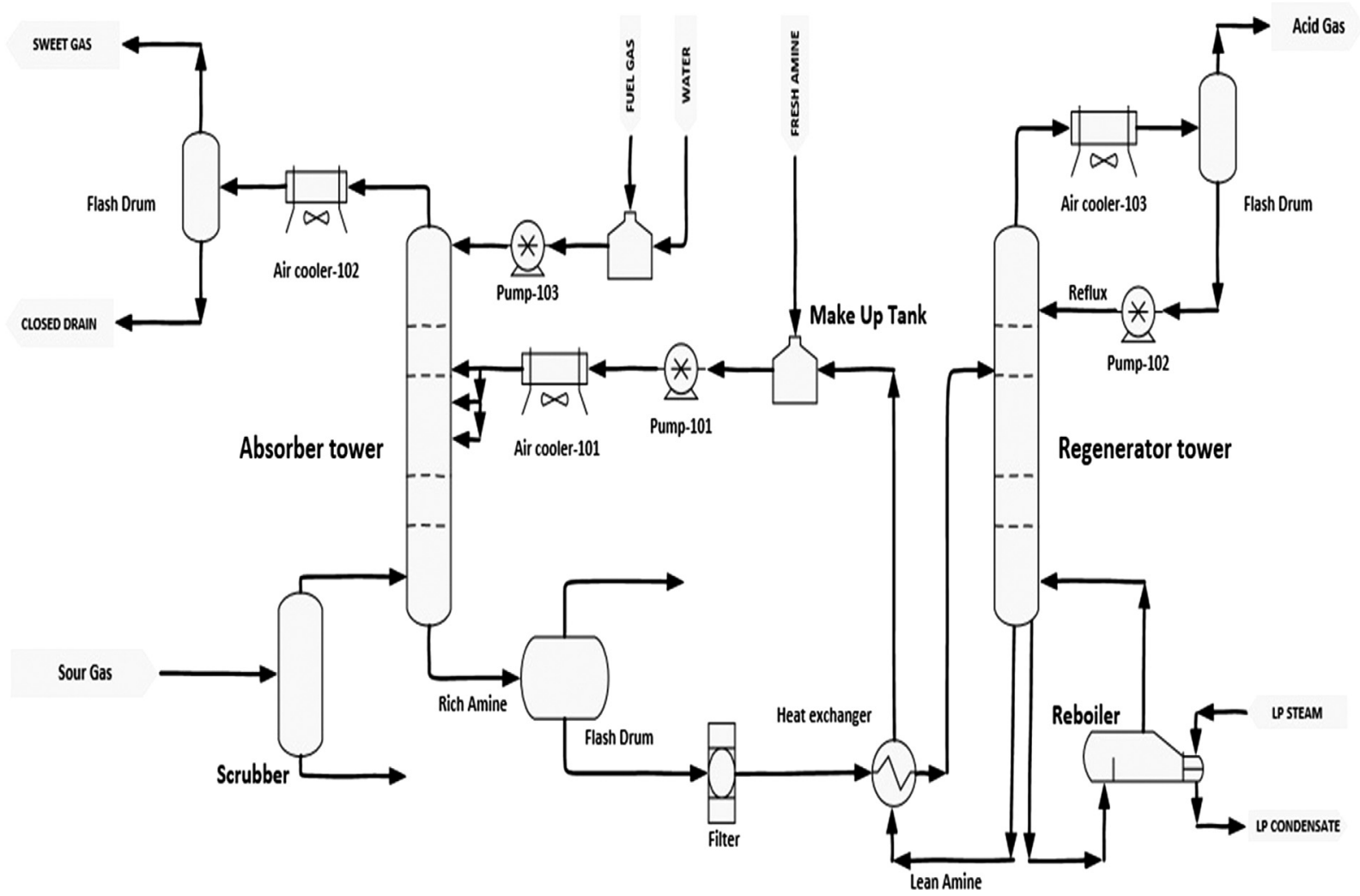

Figure 1

Process flow diagram for unit of the gas sweetening with MDEA solution.

The MDEA solvent is clear, colorless liquid and slightly pungent. It has lower regeneration cost, lower corrosion rate and the thermal and chemical degradation resistance. Typical concentration ranges for MDEA are 30\%-50\% by weight in the aqueous solution and $48 \%$ solution was used in this paper.

Sour gas, after passes through the scrubber, enters to bottom of the absorption tower. On the other hand, MDEA enters the top of the absorption tower with temperature and pressure as equal $55{ }^{\circ} \mathrm{C}$ and 53.31 barg, respectively. Another stream containing pure water is into the top of the absorption tower with the total flow rate, temperature and pressure of $448 \mathrm{~kg} / \mathrm{h}, 25{ }^{\circ} \mathrm{C}$ and $51.9 \mathrm{barg}$, respectively. The pressure of first try of absorber tower is $51.84 \mathrm{barg}$ and the pressure of the latter tray is $52.32 \mathrm{barg}$ and the pressure drop was calculated as 0.04 barg for two consecutive trays. Gas exits from the top of the absorption tower and then flows into the air cooler-102. The temperature and pressure of the gas out stream decrease and reach to $8{ }^{\circ} \mathrm{C}$ and 0.4 barg and continue to enter to the two-phase drum. Two phases separate at the operating conditions, the 
TABLE 2

Composition of sour gas based on mole fraction.

\begin{tabular}{c|c|c|c}
\hline Component & Value & Component & Value \\
\hline Methane & 0.7124 & $\mathrm{H}_{2} \mathrm{O}$ & 0.0023 \\
\hline Ethane & 0.1155 & Nitrogen & 0.0058 \\
\hline Propane & 0.0724 & $\mathrm{CO}_{2}$ & 0.0412 \\
\hline$i$-Butane & 0.0122 & $\mathrm{H}_{2} \mathrm{~S}$ & $2.40 \mathrm{E}-04$ \\
\hline$n$-Butane & 0.0211 & M-Mercaptan & $4.09 \mathrm{E}-06$ \\
\hline$i$-Pentane & 0.0057 & COS & $9.53 \mathrm{E}-07$ \\
\hline$n$-Pentane & 0.0055 & & \\
\hline
\end{tabular}

TABLE 3

Physical properties for MDEA solvent.

\begin{tabular}{c|c|c|c}
\hline Component & Value & Component & Value \\
\hline Formula & $\left(\mathrm{HOC}_{2} \mathrm{H}_{4}\right)_{2} \mathrm{NCH}_{3}$ & Weight & $8.69 \mathrm{lb} / \mathrm{gal}$ \\
\hline $\mathrm{Mw}$ & $119.17 \mathrm{~kg} / \mathrm{kmol}$ & Specific gravity, $2{ }^{\circ} \mathrm{C} / 20^{\circ} \mathrm{C}$ & $223 \mathrm{Btu} / \mathrm{lb}$ \\
\hline Boiling point at $760 \mathrm{mmHg}$ & $477{ }^{\circ} \mathrm{F}$ & Heat of vaporization & $101 \mathrm{cp}$ \\
\hline Freezing point & $-5.8^{\circ} \mathrm{F}$ & Viscosity at $20^{\circ} \mathrm{C}$ & $A=16.23$ \\
\hline Critical pressure & $5623 \mathrm{psia}$ & Constants for Antoine equation & $B=7456.8$ \\
\hline Critical temperature & $611.6{ }^{\circ} \mathrm{F}$ & & $C=311.71$ \\
\hline Density at $20{ }^{\circ} \mathrm{C}$ & $1.0426 \mathrm{gr} / \mathrm{cc}$ & & \\
\hline
\end{tabular}

temperature of $52{ }^{\circ} \mathrm{C}$ and the pressure of 51.38 barg and the sweet gas leaves from the top of the drum. The bottom flow of absorber tower containing the rich amine enters into the flash drum, because of there are very small amounts of gas in rich amine stream and excess gas leaves the main stream (which is as rich amine) at the operating temperature and pressure as $63{ }^{\circ} \mathrm{C}$ and 5.17 barg, respectively. The rich amine enters the heat exchanger amine - amine as cold fluid and heated by the amine regenerated.

Rich amine stream, after warming by heat exchanger, be sent in the fourth tray of regenerator tower. The pressure of first tray is 0.76 barg and the pressure of latter tray is 0.79 barg, while the pressure of reboiler of regenerator tower is 0.83 barg. Sour gas comes out from the top of the regenerator tower with amine vapor and the temperature reduces to $55{ }^{\circ} \mathrm{C}$ by air cooler and then amine becomes liquid in the operating conditions $55{ }^{\circ} \mathrm{C}$ and 0.689 barg and returns to the first tray of regenerator tower by pump - 102 with the pressure of 0.76 barg. Sour gas leaves the top of the flash drum. The regenerated amine stream comes out from down the regenerator tower and continues to reduce to $86.18^{\circ} \mathrm{C}$ by the heat exchanger. Stream output of the converter into the make-up tank with the flow rate of $587.945 \mathrm{kmol} / \mathrm{h}$ mixed with some fresh amine. Finally, MDEA returns to the absorption tower. Specifications and geometry of the tray towers and packed towers were shown in Tables 4 and 5, respectively. Tray tower specifications have fixed for all of trays. Also, packed tower specifications have fixed for all of packing.

\section{RESULTS AND DISCUSSION}

\subsection{Validation}

In this section, the results of our simulation were compared with industrial data. The flow rate of $\mathrm{CO}_{2}$ and $\mathrm{H}_{2} \mathrm{~S}$ in the sweet gas stream and the temperature and pressure of this main stream are listed in Table 6. Error is the ratio of the 
TABLE 4

Specifications and geometry of the tray towers.

\begin{tabular}{c|c|c|c|c|c}
\hline & Height $(\mathrm{m})$ & Diameter $(\mathrm{m})$ & Number of tray & Pressure of top tray (barg) & Pressure of down tray (barg) \\
\hline Absorber tower & 8 & 1.5 & 13 & 51.84 & 52.32 \\
\hline Regenerator tower & 12 & 1.5 & 20 & 0.76 & 0.79 \\
\hline
\end{tabular}

TABLE 5

Geometry of the packed towers.

\begin{tabular}{c|c|c}
\hline & Height of packing $(\mathrm{m})$ & Diameter $(\mathrm{m})$ \\
\hline Absorber tower & 8 & 1.5 \\
\hline Regenerator tower & 12 & 1.5 \\
\hline
\end{tabular}

difference between the industrial and simulation data to the industrial data. The error in all cases is less than $5 \%$.

\subsection{Effect of the Trays Types}

In this section, two towers, absorber and regenerator towers were considered as a column with different trays. Trays types of towers were studied such as a considered parameter in this section. Three types were used: sieve, valve, and bubble cap tray. Sieve tray is the simplest type of tray (Fig. 2a). On these trays, vapor goes to up, through several holes. In order to create more favorable conditions for the distribution of steam in the liquid and more contact of these two phases, valves or caps be installed on the holes, which ones were named valve tray and bubble cap tray, respectively (Fig. 2b and 2c). Almost large surface area and small pressure drop are two special properties of these two types of trays. Also, they can be used in the different liquid and vapor flow rates.

Figures $3 \mathrm{a}$ and $3 \mathrm{~b}$ show the flow rates of $\mathrm{CO}_{2}$ and $\mathrm{H}_{2} \mathrm{~S}$ in the sweet gas stream with different trays in the absorber and regenerator towers. Three parts show in the horizontal axis, which each part is the three different trays in the regenerator tower, while each part shows three different trays for absorber tower. As can be seen in Figure 3a, with considering the different trays types in the regenerator tower, while in all these cases the sieve tray was used in the absorber tower, it can be seen the flow rate of $\mathrm{CO}_{2}$ in the sweet gas stream with bubble cap tray is lower than other trays types in the regenerator tower. This result is valid when in all cases the bubble cap or valve tray was used in the absorber tower. On the other hand, with considering the different trays types in the absorber tower, while in all these cases the bubble cap tray was used in the regenerator tower, it can be seen the flow rate of $\mathrm{CO}_{2}$ in the sweet gas stream with bubble cap tray is lower than other trays types in the absorber tower.
TABLE 6

Comparison of our simulation with industrial data.

\begin{tabular}{c|c|c|c}
\hline Properties & Industrial & Simulation & Error (\%) \\
\hline $\mathrm{H}_{2} \mathrm{~S}(\mathrm{kmol} / \mathrm{h})$ & 0.00959 & 0.01001 & 4.37 \\
\hline $\mathrm{CO}_{2}(\mathrm{kmol} / \mathrm{h})$ & 170.87 & 169.41 & 0.85 \\
\hline Total flow $(\mathrm{kmol} / \mathrm{h})$ & 7031.8 & 7029.47 & 0.033 \\
\hline Temperature $\left({ }^{\circ} \mathrm{C}\right)$ & 52 & 51.8 & 0.38 \\
\hline Pressure $($ barg $)$ & 51.38 & 51.55 & 0.33 \\
\hline
\end{tabular}

This result is valid when in all cases the valve tray was used in the regenerator tower. But when in all cases, the sieve tray was used in the regenerator tower, the flow rate of $\mathrm{CO}_{2}$ in the sweet gas stream with valve tray is lower.

As can be seen in Figure 3b, with considering the different trays types in the regenerator tower, while in all these cases the sieve tray was used in the absorber tower, it can be seen the flow rate of $\mathrm{H}_{2} \mathrm{~S}$ in the sweet gas stream with bubble cap tray is lower than other trays types in the regenerator tower. This result is valid when in all cases the valve tray was used in the absorber tower. But when in all cases, the bubble cap tray was used in the absorber tower, the flow rate of $\mathrm{H}_{2} \mathrm{~S}$ in the sweet gas stream with sieve tray is lower. However, with considering the different trays types in the absorber tower, while in all these cases the bubble cap tray was used in the regenerator tower, it can be seen the flow rate of $\mathrm{H}_{2} \mathrm{~S}$ in the sweet gas stream with bubble cap tray is lower than other trays types in the absorber tower. This result is valid when in all cases the bubble cap or valve tray was used in the regenerator tower. It be noticed that from the lower flow rates of $\mathrm{CO}_{2}$ and $\mathrm{H}_{2} \mathrm{~S}$ it can be found that the absorption and separation by amine were done as well. In bubble cap tray more contact between two phases was achieved than other trays, so less acid gas remains in the sweet gas stream.

\subsection{Effect of the Packing}

In this section, the regenerator tower was considered as a column with bubble cap trays and the absorber tower was considered as a packed column. Packing is differently classified. The material and size of the packing are the two 


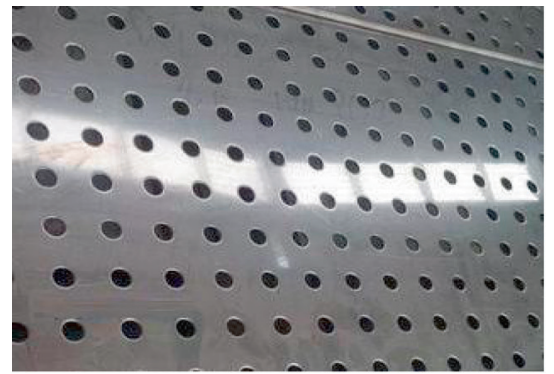

a)

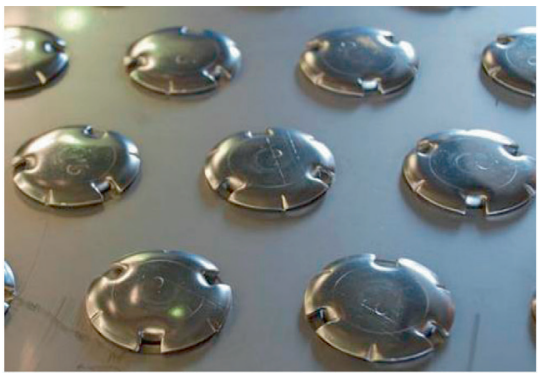

b)

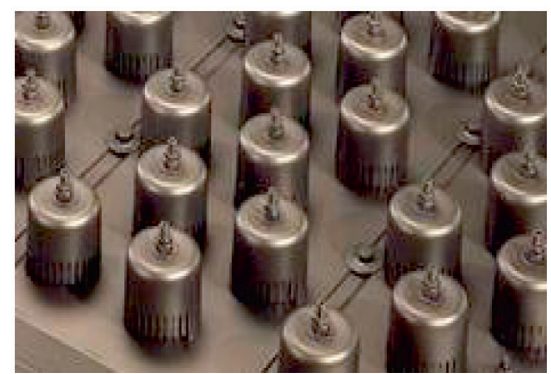

c)

Figure 2

Different types of trays: a) sieve tray, b) valve tray, c) bubble cap tray.
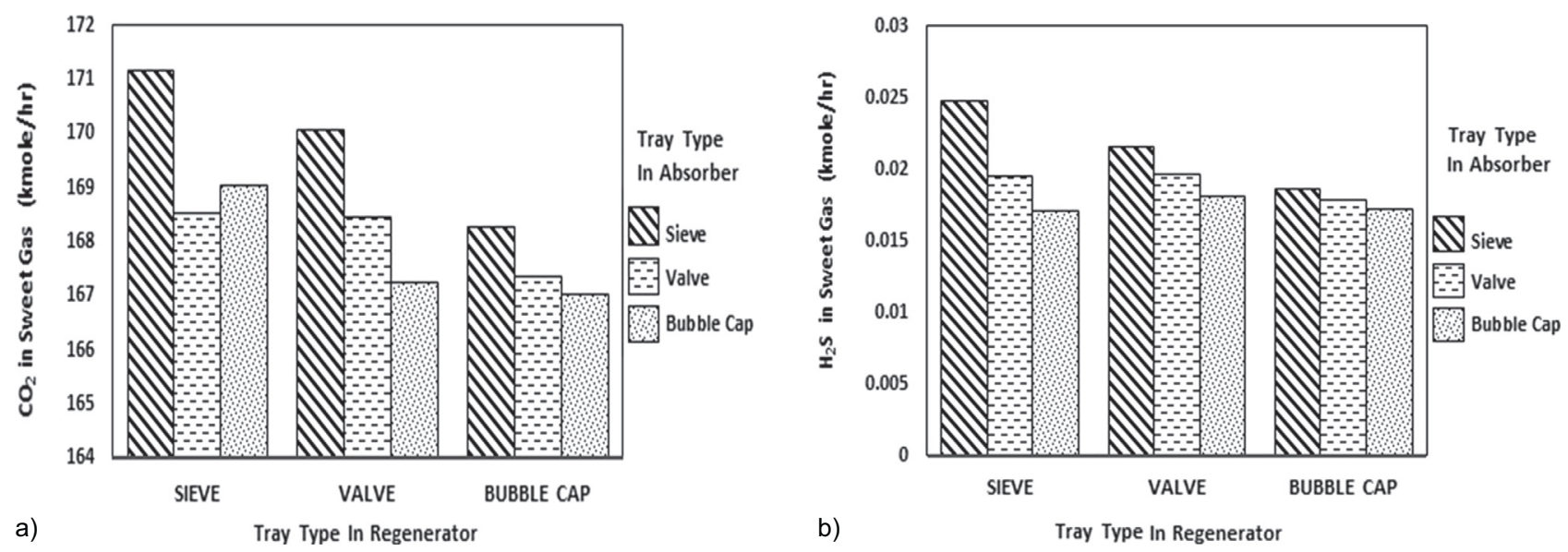

Figure 3

Effect of the different trays in the absorber and regenerator on: a) flow rate of $\mathrm{CO}_{2}$ in the sweet gas stream, b) flow rate of $\mathrm{H}_{2} \mathrm{~S}$ in the sweet gas stream.

classified parameters, which that would be considered in the next sections.

\subsubsection{Effect of the Material of the Packing}

In this section, packing is divided into three categories: ceramic, plastic, and metal. Specifications of each material were listed in Table 7. The absorber tower was used with these different types of the packing and the effects of each packing on the flow rates of $\mathrm{CO}_{2}$ and $\mathrm{H}_{2} \mathrm{~S}$ in the sweet gas stream was studied. In all cases in this section, the size of the packing is 2 inch.

Figure 4a shows the flow rate of $\mathrm{CO}_{2}$ and $\mathrm{H}_{2} \mathrm{~S}$ in the sweet gas stream for different types of the ceramic packing. It can be seen, there is a little difference in all cases. However, the flow rate of $\mathrm{CO}_{2}$ with ballast ring packing and the flow rate of $\mathrm{H}_{2} \mathrm{~S}$ with Raschig ring packing are lower than other types of packing. The liquid distribution becomes more with Raschig ring packing and so, more contact area was generated between gas and liquid. Also, Figures $4 \mathrm{~b}$ and $4 \mathrm{c}$ show the flow rate of $\mathrm{CO}_{2}$ and $\mathrm{H}_{2} \mathrm{~S}$ in the sweet gas stream for different types of the plastic and metal packing, respectively. It can be seen, above results are valid for these two cases. However, in some types such as cascade miniring, Intalox Saddles, and pall ring there is no difference for the flow rate of $\mathrm{CO}_{2}$ or $\mathrm{H}_{2} \mathrm{~S}$.

Figures $5 \mathrm{a}$ and $5 \mathrm{~b}$ show the flow rate of $\mathrm{CO}_{2}$ and $\mathrm{H}_{2} \mathrm{~S}$ in the sweet gas stream for three material types of the packing, metal, ceramic, and plastic with ballast ring and Raschig ring packing. When the ceramic ballast ring packing was used, the flow rate of $\mathrm{CO}_{2}$ in the sweet gas stream is less than the metal and plastic packing, while the flow rate of $\mathrm{H}_{2} \mathrm{~S}$ in the sweet gas stream with metal Raschig ring packing is more than other types of the packing. 
TABLE 7

Specifications of the different materials of the packing.

\begin{tabular}{c|c|c}
\hline Metal packing & Plastic packing & Ceramic packing \\
\hline Unusable for corrosive environments & Corrosion resistant & $\begin{array}{c}\text { Corrosion resistant and usable for acidic } \\
\text { and alkaline environments }\end{array}$ \\
\hline High mechanical strength & High mechanical strength & Low mechanical strength \\
\hline Usable for high temperature & Limited use at high temperature & Usable for high temperature \\
\hline Suitable wettability & Limited wettability & Suitable wettability \\
\hline
\end{tabular}

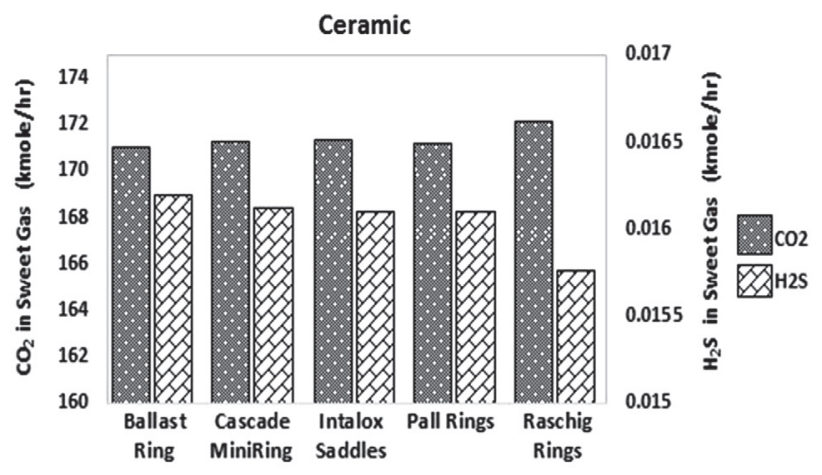

a)

Plastic

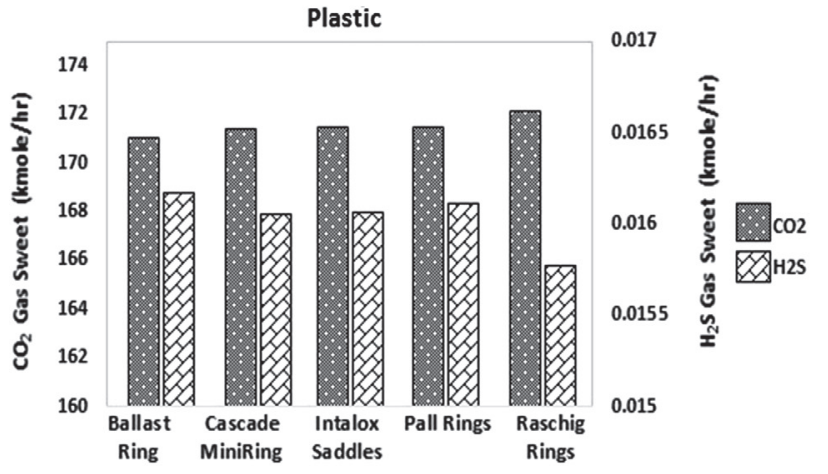

b)

$$
\text { Types of packing }
$$

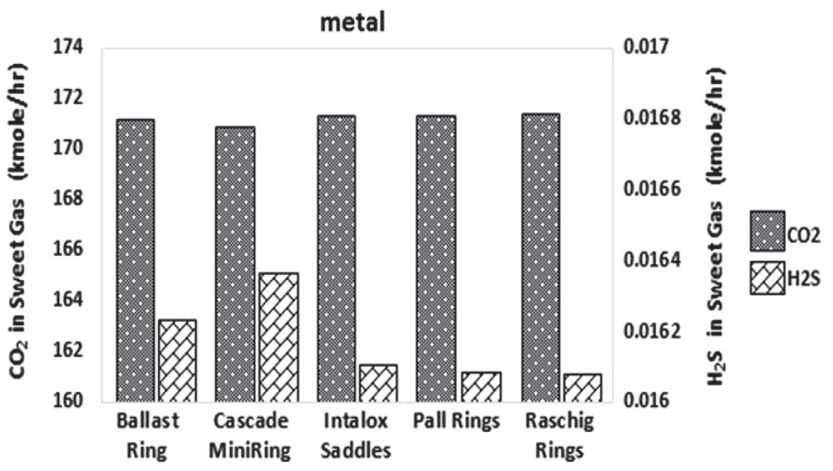

C)

Types of packing

Figure 4

Effect of the different types of packing in the absorber tower on the flow rate of $\mathrm{CO}_{2}$ and $\mathrm{H}_{2} \mathrm{~S}$ in the sweet gas stream for: a) ceramic packing, b) plastic packing, c) metal packing.

\subsubsection{Effect of the Size of Packing}

The size of the packing is an effective parameter in the amount of the empty space inside the absorber tower and so, more contact area of natural gas with amine solvent. Figures $6 \mathrm{a}$ and $6 \mathrm{~b}$ show the flow rate of the $\mathrm{CO}_{2}$ and $\mathrm{H}_{2} \mathrm{~S}$ the sweet gas stream with plastic, metal, and ceramic Raschig rings packing with different sizes. It can be seen, in all cases, with increasing the size of the packing, the flow rate of $\mathrm{CO}_{2}$ and $\mathrm{H}_{2} \mathrm{~S}$ in the sweet gas stream increases, however, this increasing in the metal packing is very small. With decreasing the size of the packing, contact area increases and so, the lower amount of $\mathrm{CO}_{2}$ remains in the sweet gas stream.

\subsection{Effect of the Tower Types}

In this section, the performance of the towers was studied with the flow rate of $\mathrm{CO}_{2}$ and $\mathrm{H}_{2} \mathrm{~S}$ in the sweet gas stream in two types of towers, tray and packed towers. In the previous sections, it found that the better performance (lower flow rate of $\mathrm{CO}_{2}$ and $\mathrm{H}_{2} \mathrm{~S}$ in the sweet gas stream) has been 


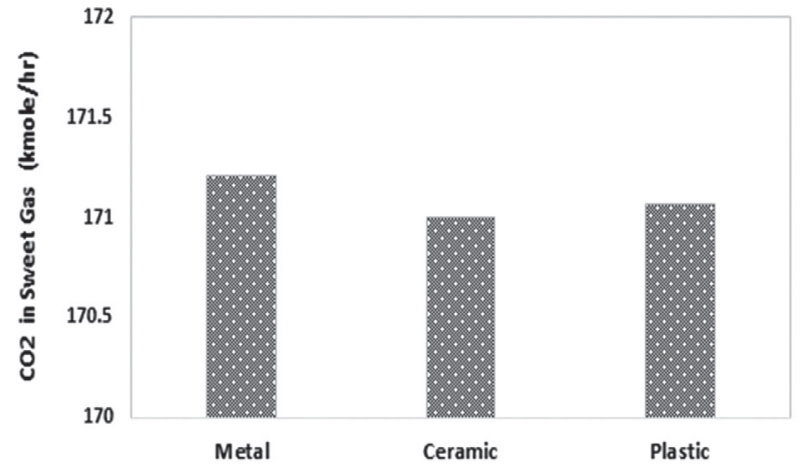

a)

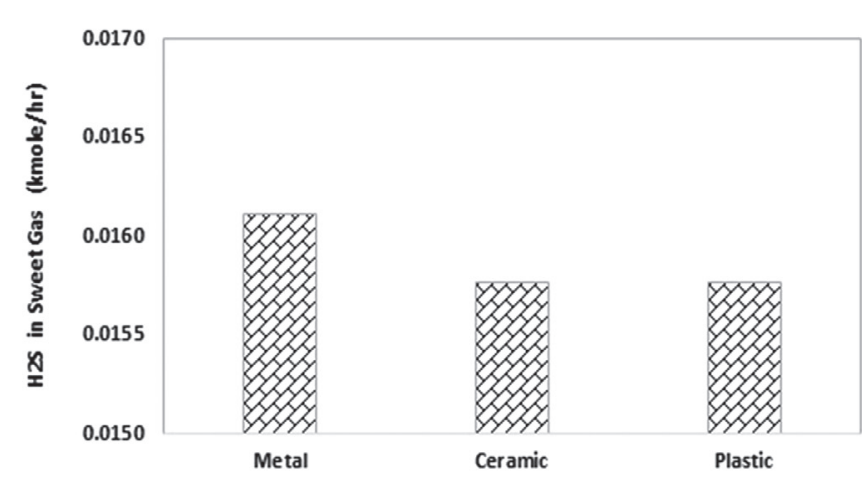

b)

Material type in Raschig Rings

Figure 5

a) The flow rate of $\mathrm{CO}_{2}$ and b) $\mathrm{H}_{2} \mathrm{~S}$ in the sweet gas stream with ballast ring and Raschig ring packing with different materials.

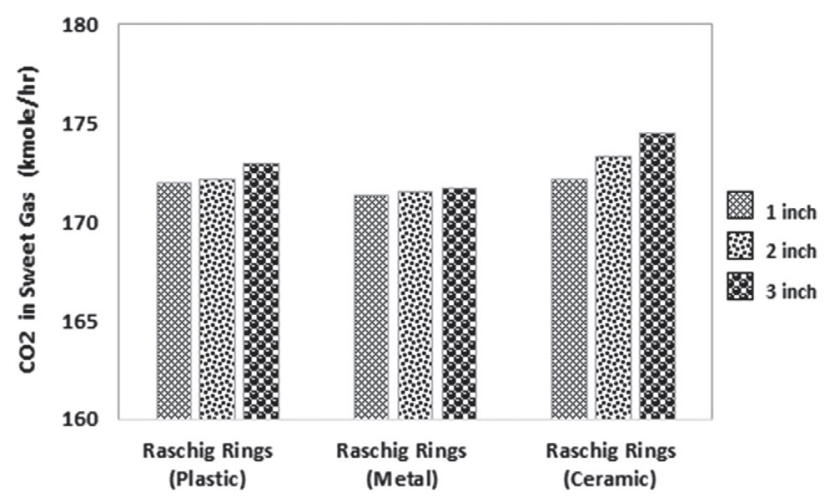

a)

Figure 6

Effect of the size of the packing in the absorber tower on: a) the flow rate of $\mathrm{CO}_{2}$ in the sweet gas stream, b) the flow rate of $\mathrm{H}_{2} \mathrm{~S}$ in the sweet gas stream.

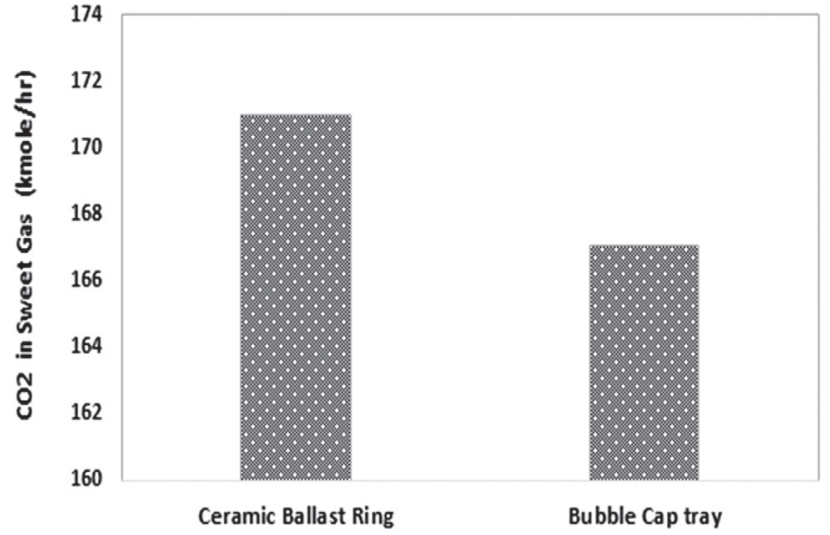

a)

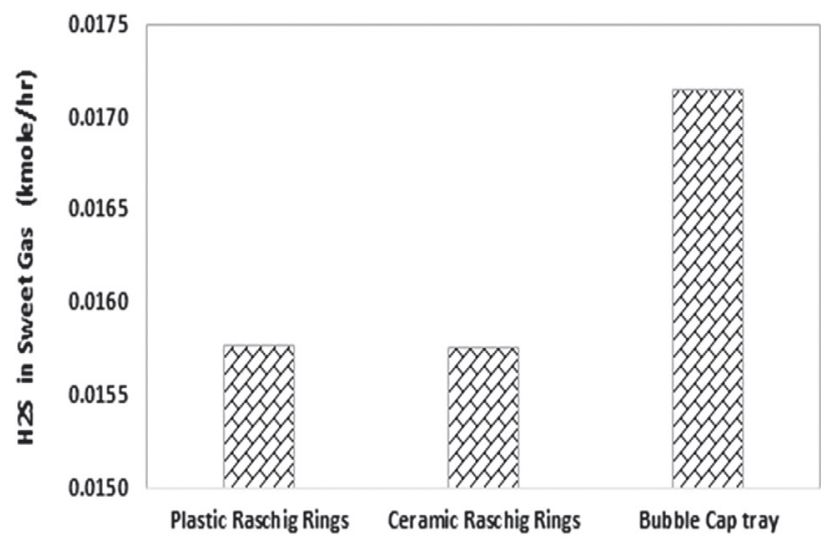

b)

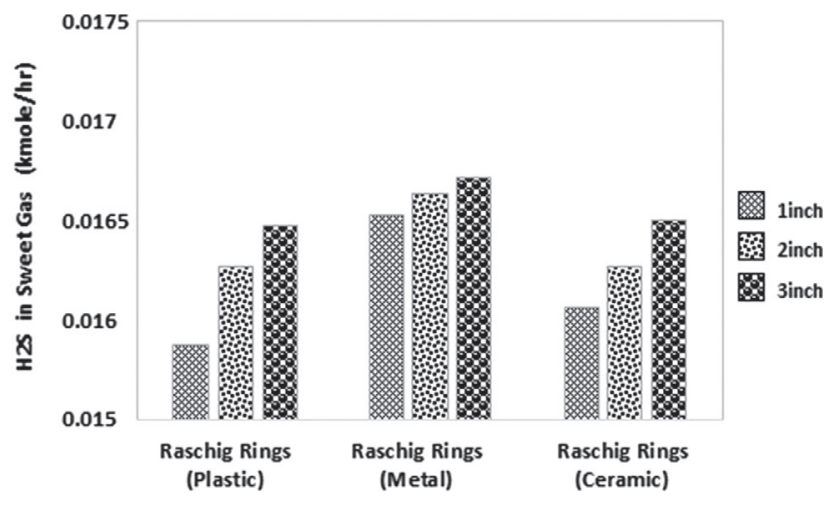

b) 
achieved with bubble cap tray for tray towers and with ceramic ballast ring and ceramic or plastic Raschig ring packing for packed towers. Figures $7 \mathrm{a}$ and $7 \mathrm{~b}$ show the flow rate of $\mathrm{CO}_{2}$ and $\mathrm{H}_{2} \mathrm{~S}$ in the sweet gas stream for tray and packed towers with different material. The size of the packing in the cases of this section is 1 inch, for better performance.

When the tray tower was used, the flow rate of $\mathrm{CO}_{2}$ in the sweet gas stream is less than the packed tower. While the flow rate of $\mathrm{H}_{2} \mathrm{~S}$ in the sweet gas stream with bubble cap tray is more than the packed tower. In packed tower, contact surface between gas and liquid is an important parameter in the performance of the tower. When liquid goes downward, total surface of the packing in the direction of diameter of tower did not wet, so the contact area is less and the acid gas may be flow upward and no contact with liquid, so $\mathrm{CO}_{2}$ separation is less.

\section{CONCLUSION}

The gas sweetening process with MDEA solvent was simulated in this work. The effect of trays types and various packing with different size were considered on the flow rate of $\mathrm{CO}_{2}$ and $\mathrm{H}_{2} \mathrm{~S}$ in the main streams and found that:

- the flow rate of $\mathrm{CO}_{2}$ in the sweet gas stream with bubble cap tray is lower than other trays types in the regenerator and absorber towers;

- the flow rate of $\mathrm{H}_{2} \mathrm{~S}$ in the sweet gas stream with bubble cap tray is lower than other trays types in the regenerator tower;

- the flow rate of $\mathrm{CO}_{2}$ with ballast ring packing and the flow rate of $\mathrm{H}_{2} \mathrm{~S}$ with Raschig ring packing are lower than other types of packing;

- in some types such as cascade miniring, Intalox Saddles, and pall ring there is no difference for the flow rate of $\mathrm{CO}_{2}$ or $\mathrm{H}_{2} \mathrm{~S}$;

- when the ceramic ballast ring packing was used, the flow rate of $\mathrm{CO}_{2}$ in the sweet gas stream is less than the metal and plastic packing;

- with increasing the size of the packing, the flow rate of $\mathrm{CO}_{2}$ and $\mathrm{H}_{2} \mathrm{~S}$ in the sweet gas stream increases;

- the flow rate of $\mathrm{CO}_{2}$ in the sweet gas stream with bubble cap tray tower is less than the packed tower;

- the flow rate of $\mathrm{H}_{2} \mathrm{~S}$ in the sweet gas stream with bubble cap tray is more than the packed tower.

\section{REFERENCES}

Abdulrahman R.K., Sebastine I.M. (2013) Natural gas sweetening process simulation and optimization: a case study of Khurmala field in Iraqi Kurdistan region, J. Nat. Gas Sci. Eng. 14, 116-120.

Abu-Zahra M.R.M., Schneiders L.H.J., Niederer J.P.M., Feron P.H.M., Versteeg G.F. (2007a) $\mathrm{CO}_{2}$ capture from power plants part I. A parametric study of the technical performance based on mono ethanolamine, Int. J. Greenhouse Cont. 1, 37-46.

Abu-Zahra M.R.M., Niederer J.P.M., Feron P.H.M., Versteeg G.F. (2007b) $\mathrm{CO}_{2}$ capture from power plants part II. A parametric study of the economical performance based on mono-ethanolamine, Int. J. Greenhouse Cont. 1, 135-142.

Borhani T.N.G., Afkhamipour M., Azarpour A., Akbari V., Emadi S.H., Manan Z.A. (2016) Modeling study on $\mathrm{CO}_{2}$ and $\mathrm{H}_{2} \mathrm{~S}$ simultaneous removal using MDEA solution, J. Indus. Eng. Chemistry 34, 344-355.

Cho H., Binns M., Min K.-J., Kim J.-K. (2015) Automated process design of acid gas removal units in natural gas processing, Comp. Chem. Eng. 83, 97-109.

Kohl A.L., Nielsen R. (1997) Gas purification, 5th edn., Gulf Professional Publishing, Texas, USA.

Maddox R.N. (1982) Gas conditioning and processing, 3rd edn., Campbell Petroleum Series, John M., Wellington, New Zealand.

Muhammad A., GadelHak Y. (2014) Correlating the additional amine sweetening cost to acid gases load in natural gas using Aspen Hysys, J. Nat. Gas Sci. Eng. 17, 119-130.

Processors G. (2004) Suppliers association (GPSA) engineering data book, Gas Processors and Suppliers Association, Tulsa, OK, USA.

Rufford T.E., Smart S., Watson G.C.Y., Graham B.F., Boxall J., Diniz da Costa J.C., May E.F. (2012) The removal of $\mathrm{CO}_{2}$ and $\mathrm{N}_{2}$ from natural gas: a review of conventional and emerging process technologies, J. Pet. Sci. Eng. 94, 123-154.

Stewart M., Arnold K. (2011) Gas sweetening and processing field manual, Gulf Professional Publishing, Waltham, MA, USA.

Tavan Y., Tavan A (2014) Performance of conventional gas sweetening process to remove $\mathrm{CO}_{2}$ in presence of azeotrope, J. $\mathrm{CO}_{2}$ Utilization 5, 24-32.

Manuscript submitted in February 2017 Manuscript accepted in June 2017 Published online in September 2017 